\title{
Nutrient composition of commercially available compared with prescription only gluten-free bread and flour mixes in England
}

\author{
Yvonne Jeanes, Rawan Rasheid, Camilla Hovland and Adele Costabile \\ University of Roehampton, London, United Kingdom
}

\section{Abstract}

There has been a global increase in gluten-free foods market and perceived health benefits are portrayed in the media. UK legislation requires wheat flour to be fortified with calcium, this is not the case for gluten-free (GF) flours. Calcium intake has been reported to be low in those consuming a GF diet. The only treatment for people with coeliac disease is a GF diet and they have a greater risk of osteoporosis. There is variable access to GF foods on prescription for this patient population in the UK. The study aimed to compare the nutrient profile of commercially available and prescribable GF breads and flour mixes.

Nutrient data were collated from the nutritional information and ingredients lists from manufacturers and online stores; $122 \mathrm{GF}$ breads and 17 GF flour mixes. White GF breads $(n=52)$, GF brown and multi-seeded GF breads $(n=70)$. Data collated from 17 GF flour mixes (12 white and 5 brown/wholemeal). Nutrient data from the nutritional information and ingredients lists were collated. Data is presented as mean \pm standard deviation.

The energy and macronutrient composition of commercially available (CA) compared with prescribable (P) white GF breads was similar. Fifty-three percent of prescribable GF white breads were fortified with calcium ( 8 out of 15$)$, whereas only $16 \%$ of CA (6 out of 37). Calcium content were similar in fortified GF white breads (CA: $178 \pm 91 \mathrm{mg} / 100 \mathrm{~g}$ and P:181 $\pm 142 \mathrm{mg} / 100 \mathrm{~g}$; NS). Only $4 \mathrm{gf}$ the 12 white flour mixes, for bread making, were fortified with calcium. Commercially available brown and multi-seeded breads had significantly less saturated fat and sugar compared with prescribable (saturated fat: CA: $0.6 \pm 0.3 \mathrm{~g} / 100 \mathrm{~g}$ and $\mathrm{P}: 0.9 \pm 0.4 \mathrm{~g} / 100 \mathrm{~g}, \mathrm{p}=0.02$; sugar: CA: $2.2 \pm 2.3 \mathrm{~g} / 100 \mathrm{~g}$ and P: $3.8 \pm 1.8 \mathrm{~g} / 100 \mathrm{~g}, \mathrm{p}=0.01)$. Sixty-seven percent of prescribable brown and multi-seeded breads were fortified with calcium (10 out of 15$)$, whereas only $13 \%$ of CA (7 out of 55) and calcium values were similar in those fortified (CA: 215 $\pm 178 \mathrm{mg} / 100 \mathrm{~g}$ and P: $194 \pm 136 \mathrm{mg} / 100 \mathrm{~g}$; NS).

This study highlights an inadequate proportion of commercially available GF breads fortified with calcium. There is a need for more GF breads to have their calcium content presented within the nutritional information on the food labels to enable people following a gluten free diet to make informed decisions. We recommend mandatory calcium fortification of GF flours to improve calcium intake in a population with an increased risk of fractures.

\section{Conflict of Interest}

Rawan Rasheid received Coeliac UK sponsored dissertation award. 